\title{
Implants in the severely resorbed mandibles: whether or not to augment? What is the clinician's preference?
}

\author{
Frits B. T. Perdijk • Gert J. Meijer • \\ Ewald M. Bronkhorst • Ron Koole
}

Received: 22 November 2010 / Accepted: 3 August 2011 / Published online: 19 August 2011

(C) The Author(s) 2011. This article is published with open access at Springerlink.com

\begin{abstract}
Introduction The aim of this study is to inventory in the Netherlands which therapy is the clinician's first choice when restoring the edentulous mandible.

Material and methods A questionnaire was sent to all Dutch Oral and Maxillofacial surgeons. As part of this, the surgeons were invited to treat five virtual edentulous patients, differing only in mandibular residual height.

Results In cases of a sufficient residual height of $15 \mathrm{~mm}$, all surgeons were in favour to insert solely two implants to anchor an overdenture. In case of a residual height of $12 \mathrm{~mm}, 10 \%$ of the surgeons choose for an augmentation procedure. If a patient was presented with a mandibular height of $10 \mathrm{~mm}$,
\end{abstract}

Electronic supplementary material The online version of this article (doi:10.1007/s10006-011-0285-6) contains supplementary material, which is available to authorized users.

F. B. T. Perdijk $(\bowtie)$

Department of Oral and Maxillofacial Surgery,

Hospital Gelderse Vallei,

P.O. Box 9045, 6710 HN Ede, The Netherlands

e-mail: f.perdijk@planet.nl

G. J. Meijer

Department of Oral and Maxillofacial Surgery,

Radboud University Nijmegen Medical Centre,

Nijmegen, The Netherlands

E. M. Bronkhorst

Department of Preventive and Curative Dentistry

and Biostatistics, Radboud University Nijmegen Medical Centre,

Nijmegen, The Netherlands

\section{R. Koole}

Department of Oral and Maxillofacial Surgery,

University Medical Centre Utrecht,

Utrecht, The Netherlands already $40 \%$ of the OMF surgeons executed an augmentation procedure. Most (80\%) surgeons prefer the (anterior) iliac crest as donor site. The choice of 'whether or not to augment' was not influenced by the surgeon's age; however, the hospital, where he was trained, did. Surgeons trained in Groningen were more in favour of installing short implants in mandibles with reduced vertical height.

Discussion As the option overdenture supported on two interforaminal implants is reimbursed by the Dutch health assurance, this treatment modality is very popular in the Netherlands. From a point of costs and to minimize bypass comorbidity, surgeons should be more reluctant in executing augmentation procedures to restore the resorbed edentulous mandible as it is dated in literature that also in mandibles with a residual height of $10 \mathrm{~mm}$ or less, solely placing implants, thus without an augmentation procedure in advance, is a reliable treatment option.

Keywords Atrophic mandible · Pre-prosthetic surgery · Bone augmentation $\cdot$ Endosseous implants

\section{Introduction}

As the dimension of the alveolar ridge is dictated by the presence of teeth, their absence induces alveolar bone resorption. In the case of complete edentulism, replacement of the natural teeth by a denture does not stop the process of continuous bone resorption. In the contrary, as a result of the unfavourable forces introduced by the denture itself, resorption of the alveolar ridge is accelerated [1]. Lack of retention of the denture, pain, eating and speech difficulties, reduced facial height, relative prognathism and collapse of lower facial soft tissue with consequential altered appearance are the common problems that patients have to deal with. 
Endosseous implants increase the stability of the denture, thereby solving a part of the above-mentioned problems. However, installing implants is only feasible if adequate alveolar bone volume is present. In case of extreme resorption of the mandible, the choice of treatment on how to restore a deficit in bone volume is still subject of discussion. Many strategies with their own specific advantages and disadvantages have been published [2, 3]. As such, for example, sulcoplasties have been proposed; by lowering of the muscular attachments of the lip, eventually in combination with releasing the mylohyoid muscle, the denture bearing area of the mandible can be enlarged [4-6].

To increase the mandibular bone volume, various augmentation procedures, such as onlay [7, 8], sandwich [9], visor [10] or submental [11] approaches, have been suggested, using an autologous bone graft or bone substitute as augmentation material. An alternative approach is the technique of alveolar distraction osteogenesis, creating an increase in bone volume without the use of bone substitutes or bone grafts [12-17]. An interesting topic is, at what point the bone volume is still thought to be sufficient to allow implant placement and at what point it is not. Nowadays, there is a tendency to use shorter implants, thereby reducing the indication for augmentation procedures [18, 19].

The aim of this study was to survey which procedure related to the extremely resorbed mandible is preferred at the present time. The extremely resorbed mandible was defined as a mandibular height in the symphyseal area of $12 \mathrm{~mm}$ or less as measured on a standardized lateral cephalogram (Fig. 1). At what mandibular height the clinician decides not only to install implants but also to perform an augmentation procedure. Does age of the surgeon, location of former training and present professional setting influence the choice of treatment? Is there a tendency to add more implants when the residual ridge decreases in height?

To survey which therapy clinicians prefer in case of an extremely resorbed mandible, a questionnaire was sent to all Dutch Oral and Maxillofacial (OMF) surgeons. Besides education and experience, all surgeons were asked to treat five virtual edentulous patients, presenting various mandibular heights.

\section{Material and methods}

Questionnaires were mailed to all 198 OMF surgeons working on 58 hospitals housing departments of OMF Surgery in the Netherlands. Of these, 129 surgeons $(65 \%)$ responded.

The questionnaire comprised two parts; the first dealt about 'age', 'location of former training' and 'present professional setting', such as university, general hospital or private practice. Questions were asked about the surgeons'

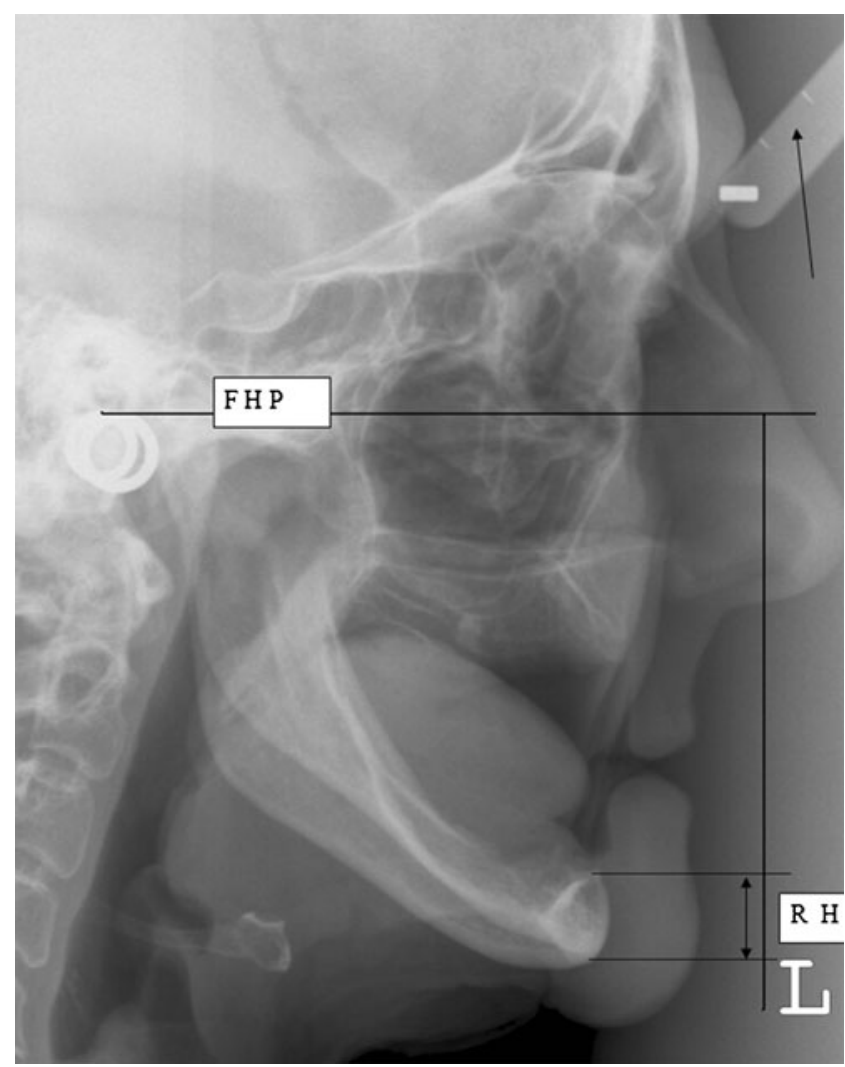

Fig. 1 An edentulous patient. $R H$ residual height in symphyseal area, in this study varying between 15 and $6 \mathrm{~mm}$

preference for a certain surgical strategy in case of a resorbed edentulous mandible (see questionnaire part I).

To further inventory the surgeons' preference, in the second part of the questionnaire, five imaginary complete edentulous patients were presented; the only parameter that varied was the mandibular height. Patient 1 represents a residual bone height in the symphyseal area of $15 \mathrm{~mm}$, patient 2 of $12 \mathrm{~mm}$, patient 3 of $10 \mathrm{~mm}$, patient 4 of $8 \mathrm{~mm}$ and patient 5 of $8 \mathrm{~mm}$. All virtual patients were in good general health, edentulous, showing a small zone of attached gingiva in combination with a shallow vestibular sulcus. Of course, all patients suffered from retention problems of their dentures. Schematic cross sections were depicted to represent the atrophic mandibles, as is shown by the Lateral Cephalometric Radiography: bone height varied from $8-15 \mathrm{~mm}$ (Fig. 1). The OMF surgeon was challenged to make an adequate treatment plan for these virtual patients.

The surgeon was faced up to choose, or solely for inserting implants, or to execute an augmentation procedure in advance (see questionnaire II). In addition, the preferred number of implants was asked for as also the method of augmentation. In the latter case, it was inventoried if autologous bone was liked superior than bone substitutes. 


\section{Statistics}

For data analysis, the statistical analysis software package SPSS 16.0.01 was used. An independent sample $t$ test was applied to analyse the relation between differences in treatment plans and 'age of the surgeon'. All other background properties of the OMF surgeons were coded as nominal variables and, therefore, the relation between these and differences in treatment plans were analysed using the Chi-square test, supplemented with the Fisher's exact test.

\section{Results}

Regarding the first part of the questionnaire, the mean age of the respondents was 46.5 years, ranging from 29 to 62 years. Most (78.6\%) were working in partnership in a general hospital. Respondents were allowed to choose more treatment possibilities for the same patient. Therefore, percentages may exceed 100\% (Figs. 2, 3, 4 and 5).

The sulcoplasty, as a single surgical method to improve patient's satisfaction, is hardly used anymore. However, in combination with, or as a secondary procedure after implant placement, the sulcoplasty has still an important role $(52 \%$ of the respondents uses this method incidental, $18 \%$ regularly). To improve the available bone volume, $57 \%$ of the respondents are in favour of the onlay method (Fig. 2). As second best, the sandwich method is regularly used $(10 \%)$. Only few colleagues are in favour of the submental method $(5 \%)$ or the visor osteotomy $(4 \%)$.

To harvest an autologous bone graft, $80 \%$ of the respondents are in favour of the (anterior) iliac crest as donor site. Only sparsely the tibia $(1 \%)$ or cranium bone $(1 \%)$ is chosen (Fig. 3).

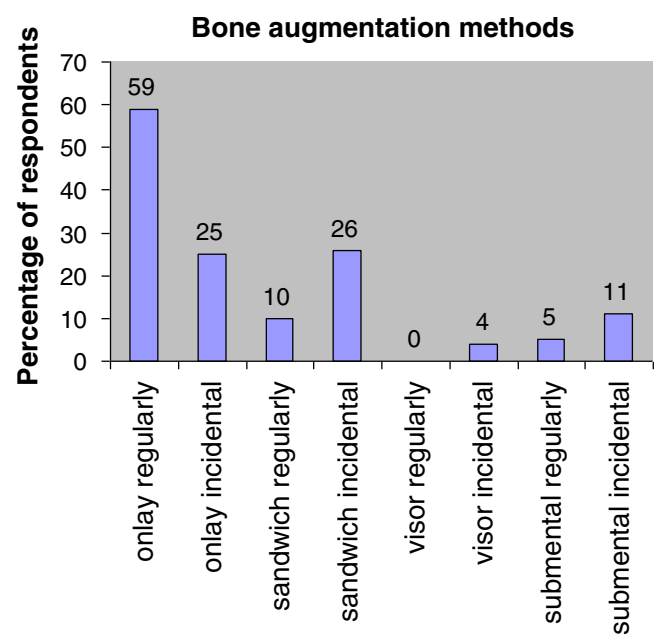

Fig. 2 Different bone augmentation methods used by Dutch OMF surgeons in cases of insufficient mandibular bone height

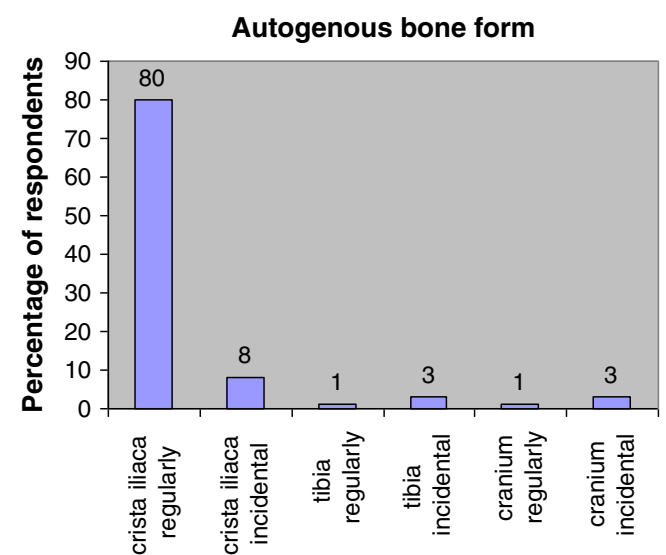

Fig. 3 The choice of Dutch OMF surgeons to harvest autologous bone grafts

As a bone substitute, Bio-Oss ${ }^{\circledR}$ is used regularly $(39 \%)$, Cerasorb ${ }^{\circledR}$ sometimes $(12 \%)$ and other bone substitutes hardly ever. As an augmentation technique, only few colleagues use vertical distraction regularly $(12 \%)$ or incidentally (23\%). Intraosseous distraction devices are more popular (19\%) than extraosseous ones $(3 \%)$.

For the edentulous mandible with sufficient bone height, placing two permucosal dental implants at the position of the former canines is preferred by most of the respondents (96\%). However, also the option of three, four and six interforaminally placed implants was selected (Fig. 4).

A bar suprastructure with overdenture is the first choice (78\%) followed by ball attachments (63\%). Fixed bridgework is not often indicated in the Netherlands (8\%; Fig. 5).

With respect to the second part of the questionnaire, all five virtual patients, as presented, suffered from an atrophic mandible, a small zone of attached gingiva, a small vestibular sulcus and an insufficient retention of their lower dentures. The following results were found (Fig. 6):

Patient 1. Complete edentulism, bone height symphysis area of $15 \mathrm{~mm}$.

Most surgeons inserted two implants (85\%). Others preferred three $(6 \%)$, four implants (7\%) or six implants (1\%; Fig. 6). Sulcoplasty, as single therapy, was only chosen by one surgeon.

Patient 2. Complete edentulism, bone height symphysis area of $12 \mathrm{~mm}$.

Again, most surgeons inserted two implants $(65 \%)$ as others inserted three implants $(10 \%)$, four implants (14\%) or six implants (1\%). In this case, $10 \%$ of the surgeons preferred to augment the mandible in advance of implant placement using autologous bone as an onlay graft (Fig. 6).

Patient 3. Complete edentulism, bone height symphysis area of $10 \mathrm{~mm}$. 
Fig. 4 Number of implants placed in the edentulous mandible
Number of implants in cases of sufficient bone height

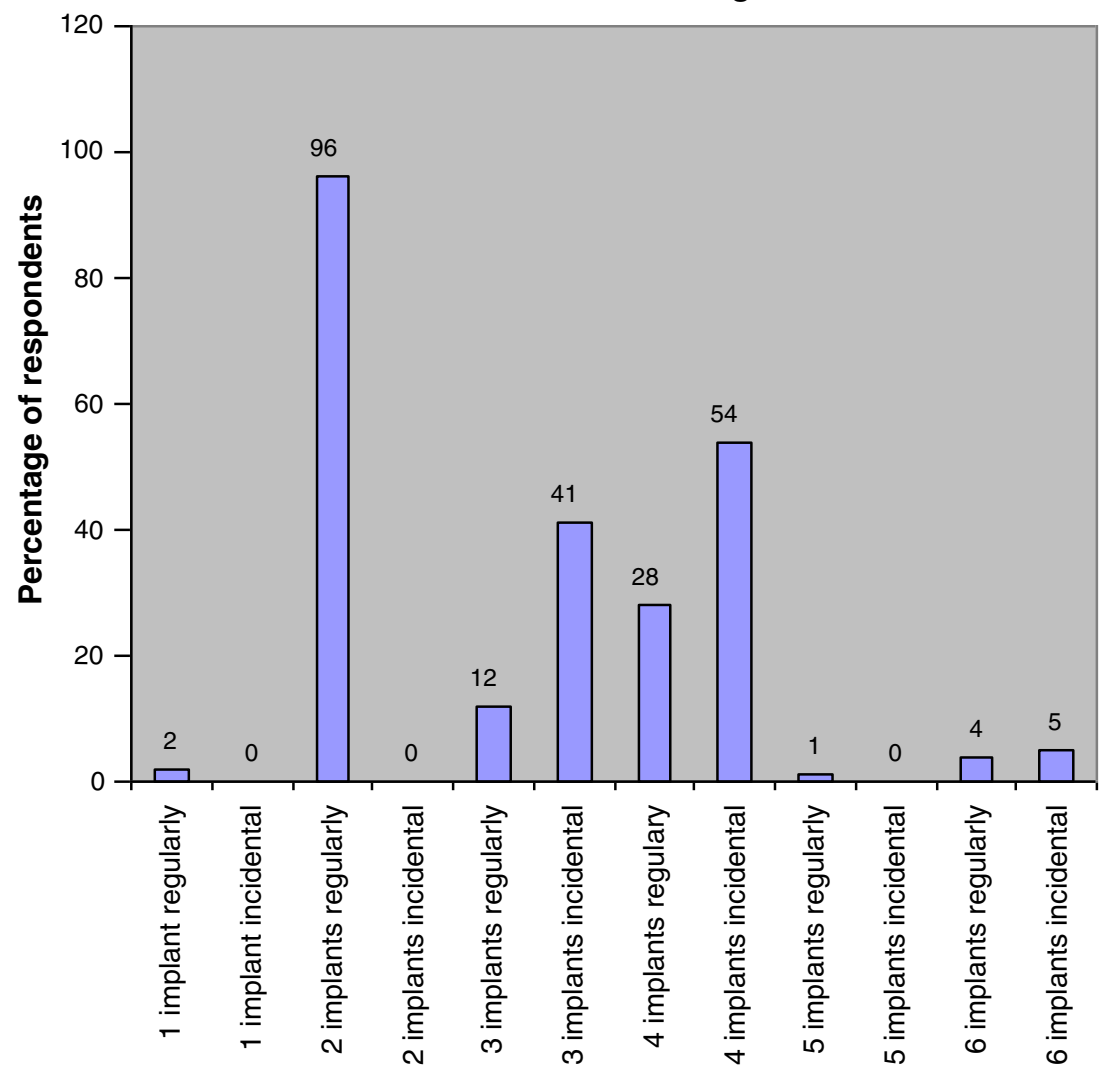

Also, in the case of a mandibular height of $10 \mathrm{~mm}$, placing solely implants is the first choice for $60 \%$ of the surgeons; most inserted two implants $(28 \%)$, others three implants (11\%), four implants $(19 \%)$ or even six implants (1\%; Fig. 5). Already $40 \%$ of the surgeons were in favour of an augmentation procedure in advance of implant placement; $28 \%$ for the onlay procedure, $6 \%$ for the sandwich method, $2 \%$ for the submental augmentation and $4 \%$ for the distraction procedure.

Patient 4. Complete edentulism, bone height symphysis area of $8 \mathrm{~mm}$.

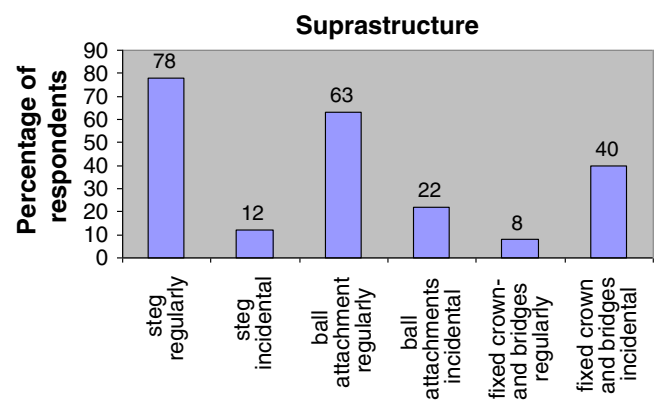

Fig. 5 Suprastructure on implants in the edentulous mandible
The majority of the respondents $(71 \%)$ were in favour of first augmenting the mandible; $52 \%$ preferred the onlay procedure, $10 \%$, the sandwich method, $4 \%$, the submental augmentation and 5\%, the distraction procedure. Just installing two implants without pre-implant surgery was suggested by $11 \%$ of the surgeons, three implants by $4 \%$ and four implants by $13 \%$ of the colleagues (Fig. 6).

Patient 5. Complete edentulism, bone height symphysis area of $6 \mathrm{~mm}$.

Only $9 \%$ of the respondents choose for implant placement without augmentation procedures; $2 \%$ preferred the option of two or three implants, $5 \%$ choose for four implants. The majority (91\%) liked to improve the vertical height in advance of implant placement (Fig. 5); with an onlay graft (64.1\%), sandwich method (8\%), submental augmentation $(8 \%)$ or vertical distraction $(2 \%)$.

Statistical testing

Neither 'age of surgeon' nor the variables 'location of former training' and 'present professional setting' 
Fig. 6 The choice of Dutch OMF surgeons to place two, three, four or six implants or to first restore the available bone volume in relation to the vertical residual bone height

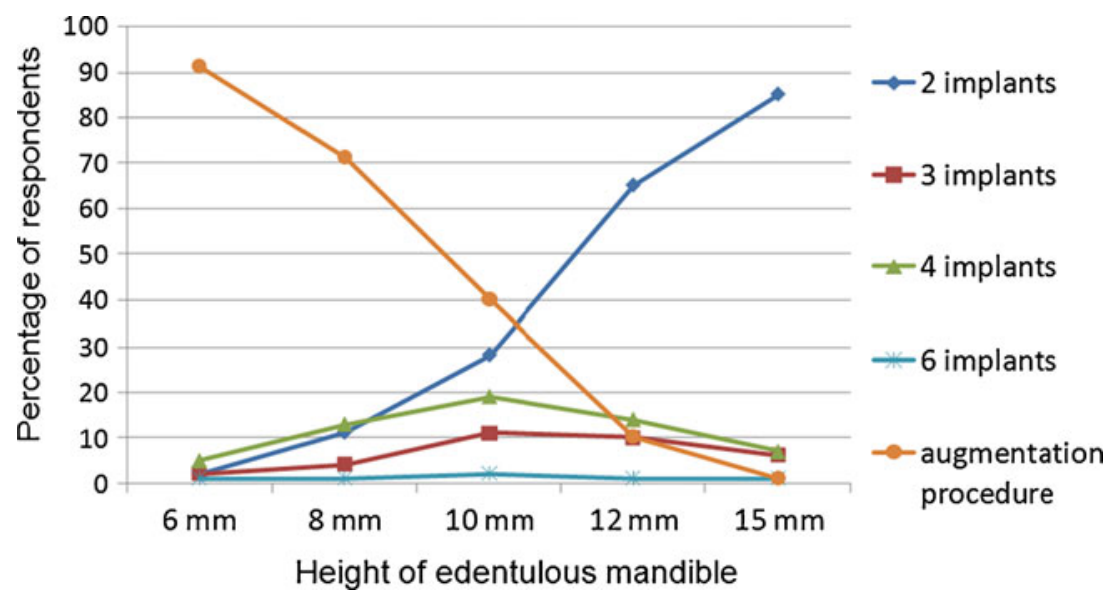

explain the preference in choice for treatment; for a relative simple overdenture in the Netherlands versus complete preimplant rehabilitation using augmentation procedures in combination with fixed and sometimes immediate loaded appliances in other countries [22, 23].

The outcome of the questionnaires shows that the sulcoplasty, as a single surgical method, is hardly used anymore. Nowadays, the most favourable approach to restore retention of a denture is to insert two implants. From review of the literature, it seems evident that many treatment concepts involving mandibular overdentures supported by endosseous implants are based on empirical experiences or are merely on opinions of members of individual centres [22]. If the patient desires increased stability of the mandibular denture and improved chewing ability, two implants connected by a bar in the interforaminal region supporting an overdenture are sufficient as a general rule. However, when using only two implants, a rotational movement of the denture is still feasible because the denture is supported by both the mucosa and the implants. To increase the stability of the denture, more implants can be placed, thereby making the denture completely implant-borne [24].

This article inventories at what mandibular height clinicians choose for first executing an augmentation procedure before installing implants (Fig. 6). In the case of a mandibular height of 12 and $15 \mathrm{~mm}$, both in the questionnaire as in the treatment of the virtual patients, the majority of the respondents prefer the option of inserting solely two implants. In the case of a vertical bone height of $10 \mathrm{~mm}$, the choice for first performing an augmentation procedure became real. Already $40 \%$ of the respondents choose for augmenting the mandible in advance of implant placement. The other $60 \%$ were in favour of just installing implants. About the topic at what mandibular height an augmentation procedure is required, literature is not conclusive. Although numerous studies have described the there is no reimbursement for fixed restorations. This may 
outcome results of dental implants in the edentulous mandible, there have been few prospective studies designed as randomized clinical trials that compare different treatment modalities to restore the severely resorbed mandible. As such, in a prospective study, Stellingsma et al. (2004) compared three treatment methods in patients with an average mandibular bone height of $9.7 \pm 1.4 \mathrm{~mm}$ [24]. In one group, they installed four short implants; in another group, first an onlay procedure was performed after which four regular-sized implants were placed in a secondary procedure. In the latter group, $10 \%$ of the implants have been lost compared to $0 \%$ in the group installing just four short implants. Also, retrospective studies $[25,26]$ showed acceptable survival rates of between $92 \%$ and $94 \%$ survival rate after 10 years of loading using at least four short implants to support a fixed implant-supported prosthesis or overdentures. In the study of Deporter et al. (2002), overdentures were supported by three short implants showing a survival rate of $93 \%$ after 10 years. [27] The question pops up if these successes also will be achieved if installing just two implants.

For the virtual patient having a low mandibular height (6 or $8 \mathrm{~mm})$, a minority of the respondents $(29 \%$ and $9 \%$, respectively) choose for solely implant placement. Besides the risk of implant loss, also the mandible may fracture. However, this risk is relatively low. Recently, an inventory by Soehardi et al. on the number of fractures that occurred in conjunction with implants placed in edentulous patients in the Dutch population during the period 1980-2007 elucidated an incidence of only $0.033 \%$ [28]. Nevertheless, it was stressed that if a fracture does occur, this complication is difficult to treat $[16,28]$.

To improve the available bone volume, most of the respondents are in favour of the onlay method using iliac crest bone. The disadvantage of harvesting a bone graft is obvious; it demands an extra operation resulting in a prolonged operation time, extra costs and more morbidity. Therefore, a shift to using short implants is a logical next step.

An interesting point is that the age of the surgeon did not influence the choice whether "to augment or not". This means that older surgeons evaluated their therapies to the present state of art in pre-implant surgery, and also that younger surgeons have probably less acquaintance to "older" techniques like sulcoplasties, visor or sandwich augmentations. Surprisingly, the 'location of training' was of significant influence. Surgeons trained in education clinics that advocate the placement of short implants followed the same strategy in the treatment of the virtual patient with a mandibular height of $10 \mathrm{~mm}$.

Although numerous studies have described the outcome results of dental implants in the edentulous mandible, there have been few prospective studies designed as randomized clinical trials that compare different treatment modalities. There is a tendency to insert short implants in case the mandibular height in full edentulous patients is even lower than $10 \mathrm{~mm}$. In a recently published case report, even four implants with a length of only $5.5 \mathrm{~mm}$ in length were placed in an extremely resorbed mandible [29]. To bypass the comorbidity that is linked to augmentation procedures using autologous bone, future prospective studies should concentrate on the issue if placement of only two implants is a reliable option for the extremely resorbed edentulous mandible having a residual height of less than $10 \mathrm{~mm}$.

In conclusion, a $12-\mathrm{mm}$ residual bone height in the symphyseal area is the turning point for most of the colleagues whether to perform augmentation procedures or place solely implants. Ongoing research in favour of placing short implants will decrease this turning point, maybe even to a level of $8 \mathrm{~mm}$ residual bone height, or less, thereby reducing costs and patient morbidity.

Conflict of interest The authors declare that they have no conflict of interest.

Open Access This article is distributed under the terms of the Creative Commons Attribution Noncommercial License which permits any noncommercial use, distribution, and reproduction in any medium, provided the original author(s) and source are credited.

\section{References}

1. Tallgren A (1972) The continuing reduction of the residual alveolar ridge in complete denture wearers; a mixed longitudinal study covering 25 years. J Prosthet Dent 27:120-132

2. Jennings DE (1989) Treatment of the mandibular compromised ridge: a literature review. J Prosthet Dent 61:575-579

3. McCord JF, Grant AA, Quayle AA (1992) Treatment options for the edentulous mandible. Eur J Prosthodont Resto Dent 1:19-23

4. Szabo J (1916) Methode zur Verhinderung des Verursachens der durchtrennten Mundschleimhaut. Österr Vierteljahresschr Zahnheilkd 32:244-249

5. Tideman H (1973) Vestibulum plastiek met het vrije mucosa transplantaat. Dissertation. University of Amsterdam

6. Hall HD (1971) Vestibuloplasty, mucosal grafts (palatal and buccal). J Oral Surg 29:786-791

7. Neukam FW, Scheller H, Günway H (1989) Experimentelle und klinische Untersuchungen zur Auflagerungsostoeplastiek in Kombination mit enossalen Implantaten. Z Zahnärtzl Implantol 5:235-241

8. Verhoeven JW, Cune MS, Terlou M, Zoon MA, De Putter C (1997) The combined use of endosteal implants and iliac crest onlay grafts in the severely atrophic mandible: a longitudinal study. Int J Oral Maxillofac Surg 26:351-357

9. Stoelinga PJW, Tideman H, Berger JS, de Koomen HA (1978) Interpositional bone graft augmentation of the atrophic mandible: a preliminary report. J Oral Surg 36:30

10. Härle F (1975) Visor osteotomy to increase the absolute height of the atrophied mandible. A preliminary report. J Maxillofac Surg 3 (4):257-260

11. Gutta R, Waite PD (2008) Cranial bone grafting and simultaneous implants: a submental technique to reconstruct the atrophic mandible. Br J Oral Maxillofac Surg 46(6):477-479 
12. Ilizarov GA (1989) The tension-stress effect on the genesis and growth of tissues. Part I. The influence of stability of fixation and soft tissue preservation. Clin Orthop 238:249-281

13. Chin M, Toth BA (1996) Distraction osteogenesis in maxillofacial surgery using internal devices: review of five cases. J Oral Maxillofac Surg 54:45-53

14. Perdijk FBT, van Strijen PJ (2001) Augmentation of severe mandibular atrophy by vertical distraction osteogenesis. In: Samchukov M, Cope J, Cheraskin A (eds) Mandibular distraction osteogenesis. Mosby, St. Louis, pp 433-437

15. Hidding J, Lazar F, Zöller JE (1999) Initial outcome of vertical distraction osteogenesis of the atrophic alveolar ridge. Mund Kiefer Gesichtschir 3(Suppl 1):S79-S83

16. Raghoebar GM, Heydenrijk K, Vissink A (2000) Vertical distraction of the severely resorbed mandible. The Groningen distraction device. Int J Oral Maxillofac Surg 29(6):416-420

17. Krenkel C, Grunert I (2009) The Endo-Distractor for preimplant mandibular regeneration. Rev Stomatol Chir Maxillofac 110 (1): $17-26$

18. Stellingsma K, Raghoebar GM, Meijer HJ, Stegenga B (2004) The extremely resorbed mandible: a comparative prospective study of 2-year results with 3 treatment strategies. Int J Oral Maxillofac Implants 19(4):563-577

19. Adell R, Lekholm U, Rockler B, Brånemark PI (1981) A 15-year study of osseointegrated implants in the treatment of the edentulous jaw. Int J Oral Surg 10(6):387-416

20. Feine JS, Carlsson GE, Awad MA, Chehade A, Duncan WJ, Gizani S, Head T, Lund JP, MacEntee M, Mericske-Stern R, Mojon P, Morais J, Naert I, Payne AG, Penrod J, Stoker GT, Tawse-Smith A, Taylor TD, Thomason JM, Thomson WM, Wismeijer D (2002) The McGill consensus statement on overdentures. Mandibular two-implant overdentures as first choice standard of care for edentulous patients. Montreal, Quebec, May 24-25, 2002. Int J Oral Maxillofac Implants 17(4):601-602
21. Carlsson GE, Kronström M, de Baat C, Cune M, Davis D, Garefis P, Heo SJ, Jokstad A, Matsuura M, Närhi T, Ow R, Pissiotis A, Sato H, Zarb GA (2004) A survey of the use of mandibular implant overdentures in 10 countries. Int J Prosthodont 17(2):211217

22. Batenburg RH, Meijer HJ, Raghoebar GM, Vissink A (1998) Treatment concept for mandibular overdentures supported by endosseous implants: a literature review. Int J Oral Maxillofac Implants 13(4):539-545

23. Stellingsma C, Vissink A, Meijer HJ, Kuiper C, Raghoebar GM (2004) Implantology and the severely resorbed edentulous mandible. Crit Rev Oral Biol Med 15:240-248

24. Stellingsma C, Meijer HJ, Raghoebar GM (2000) Use of short endosseous implants and an overdenture in the extremely resorbed mandible: a five-year retrospective study. J Oral Maxillofac Surg 58:382-387

25. Friberg B, Gröndahl K, Lekholm U, Brånemark PI (2000) Longterm follow-up of severely atrophic edentulous mandibles reconstructed with short Brånemark implants. Clin Implant Dent Relat Res 2(4):184-189

26. Triplett RG, Mason ME, Alfonso WF, McAnear JT (1991) Endosseous cylinder implants in severely atrophic mandibles. Int J Oral Maxillofac Implants 6(3):264-269

27. Deporter D, Watson P, Pharoah M, Todescan R, Tomlinson G (2002) Ten-year results of a prospective study using poroussurfaced dental implants and a mandibular overdenture. Clin Implant Dent Relat Res 4(4):183-189

28. Soehardi A, Meijer GJ, Manders R, Stoelinga PJW (2011) An inventory of mandibular fractures associated with implants in atrophic edentulous mandibles; a survey among Dutch OMFsurgeons. Int J Oral Maxillofac Implants (in press)

29. Lopes N, Oliveira DM, Vajgel A, Pita I, Bezerra T, Vasconcellos RJ (2009) A new approach for reconstruction of a severely atrophic mandible. J Oral Maxillofac Surg 67:2455-2459 